\section{Research Square}

Preprints are preliminary reports that have not undergone peer review.

They should not be considered conclusive, used to inform clinical practice, or referenced by the media as validated information.

\title{
Electrochemical Impedance Spectroscopy Behavior of Aluminum Alloys 2024 and 6061 in Rainwater
}

sahib Mohammed mahdi ( $\sim$ saheb.m.mahdi@uomustansiriyah.edu.iq )

Mustansiriyah University Faculty of Engineering https://orcid.org/0000-0003-3642-9821

\section{Saraa M. Mohammed}

Mustansiriyah University Faculty of Engineering

\section{Research Article}

Keywords: aircraft aluminum alloy, solution treatment, Electrochemical impedance spectroscopy test, EIS curve

Posted Date: September 21st, 2021

DOI: https://doi.org/10.21203/rs.3.rs-884255/v1

License: (c) (i) This work is licensed under a Creative Commons Attribution 4.0 International License. Read Full License 


\section{Abstract}

In the present work the electrochemical resistance spectroscopy behavior of aluminum alloy 2024 and 6061 in rainwater, was studied before and after solution heat treatment at room temperature $\left(25^{\circ} \mathrm{C}\right)$. If the resistance decreases, the corrosion becomes faster, and vice versa. The equivalent circuits was of type Constant Phase Element (CPE) and the highest resistance value gets for alloy 2024 aged at $250^{\circ} \mathrm{C}$ for 2 hours, and the highest resistance value was for alloy 6061 aged at $250^{\circ} \mathrm{C}$ for 1 hour. As for the values of capacitance, the highest amplitude value was for alloy 2024 aged at $300^{\circ} \mathrm{C}$ for two hours, and the highest value gets for capacity for alloy 6061 aged at $150{ }^{\circ} \mathrm{C}$ for two hours.

\section{Introduction}

There are two Al alloy types considered, such as the wrought and cast aluminum alloys [1].In general, the heat treatment indicates any cooling and heating processes, which are carried out to change the metallurgical structure, mechanical characteristics, or residual stress state of the metallic product. In the case where the term has been applied to the Al alloys, nonetheless, its utilization is often restricted to particular processes which are utilized for increasing the hardness and the strength of the precipitation-hardenable cast and wrought alloys [2]. Solution heat treatment of the Al alloys provides the possibility for maximal hardening solute concentration for dissolving to the solution. Such a process is often performed through heating alloy to the temperature where there is a single, solid phase. By performing such a process, the atoms of the solute which have been, at first, a portion of a 2 phase solid solution are dissolved to solution and produced a single phase. As soon as the alloy is heated to the suggested temperature of solutionizing, it will be quenched at a fast rate in a way that the atoms of the solute have no sufficient time for precipitating out of that solution. Due to the quenching, a supersaturated solution is formed between the Al matrix and the solute $[3,4]$.In heat treatment of the solution, this alloy has been heated up to the temperature which is sufficiently high for putting soluble alloying elements into the solution. Post held at the treating temperature of the solution for sufficient time for the diffusion of the atoms of solute to the matrix of the solvent to take place, it's quenched to a lower degree of the temperature (for example, room temperature) for keeping the elements of alloying trapped within the solution. Throughout the aging, the elements of the alloying are trapped in the precipitate of the solution for forming an even distribution of highly fine particles. Some of the alloys of Al are hardened at room temperature in a few days in a process which is referred to as natural aging whereas others will be aged artificially through the heating to the intermediate temperatures, in the case where it has been aged through the re-heating to an intermediate degree of the temperature, it will be designated as T6 condition (which indicates that the solution is heat-treated and aged artificially) [5].The goal of the solution heat treatment of $\mathrm{Al}$ is obtaining maximal hardening solute concentration, like $\mathrm{Zn}, \mathrm{Mg}$, and $\mathrm{Cu}$, in the solution through heating alloy to a degree of the temperature where the single-phase is going to be produced. Through performing this process, the atoms of the solute which has been, at the first portion of a 2-phase solid solution have dissolved back to solution and produce a single phase which is in the equilibrium. As soon as the alloy was held for a long time to ensure the full solutioning and the homogenous state, it's quenched fast, for the atoms of solute not having a sufficient amount of time for the precipitation out of the solution. As a result, there is a supersaturated solution between the Al matrix and solute [6, 7]. All non-heat-treatable alloys have a high resistance to general corrosion. Heattreatable wrought alloys have a significantly lower resistance to general corrosion. These include all $2 x x x$ series alloys (Al-Cu, Al-Cu-Mg, Al-Cu-Si-Mg) in which copper is a major alloying element. As a result of the presence of copper in this type of alloy, the resistance decreases and therefore preventive measures must be taken [8]. However, those from the 6xxx series, which are medium strength alloys based on the quasi-binary Al-Mg2Si system, provide a high overall corrosion resistance equal to or close to a non-heat-treatable alloy. Aluminum alloys (2000 series) that contain copper as a major element used in alloying in general have less corrosion resistance than those alloys that do not contain these elements. For this reason, it is usually difficult to prevent corrosion of aluminum alloys in this series [9]. Corrosion in 
aluminum and its alloys, it is usually of a local nature and is most commonly caused by pitting or in areas that come into contact with dissimilar minerals in a conducive environment (sea water or road splash containing dissolving salts) [10]. (EIS) it is a distinctly touchy definition technique used to non-destructively evaluate the electrical reaction of chemical structures. EIS systems reflect the chemical system's time reaction using alternating current (AC) voltages of low amplitude over a range of frequencies. Using an electrode setup including an operating, reference, and counter electrodes a known voltage is passed voltage of the counter electrodes is passed through an electrolytic solution from the working electrode and into the counter electrode. Quantitative measurements are provided through the EIS and allow the evaluation at the electrode interface and in the electrolytic solution of small-scale chemical mechanisms. Therefore, in the study of batteries, corrosion, and so on, EIS is useful in evaluating a wide variety of dielectric and electrical characteristics of components [11].

\section{Experimental Procedure:}

\subsection{Aluminum alloys}

The materials used in this study are aircraft aluminum alloys of a certain grade (2024 and 6061). The chemical compositions of these alloys were analyzed with spectromax, and the results are reported in "Table 1." The results were found to be consistent with the standard values [12]. This research was carried out in Rain Water. The plate was cut using a water jet to match the dimensions of the sample holder. The disc-shaped specimens are $(\varphi 25 \times 2 \mathrm{~mm})$ in size.

Table 1

Chemical analysis of the aircraft aluminum alloys

\begin{tabular}{|llllllllllll|}
\hline Element\% & Si\% & Fe\% & Cu\% & Mn\% & Mg\% & Cr\% & Ni\% & Ti\% & Zn\% & Pb\% & Al\% \\
\hline AA2024 & 0.0501 & 0.178 & 4.70 & 0.515 & 1.46 & 0.0082 & 0.0093 & 0.0240 & 0.209 & 0.0073 & 92.8 \\
\hline AA6061 & 0.596 & 0.533 & 0.257 & 0.124 & 0.990 & 0.121 & 0.0098 & 0.132 & 0.0269 & 0.0124 & 97.2 \\
\hline
\end{tabular}

\subsection{Water media}

Rainwater was used as a corrosive medium in this study to see how solution treatment affected the corrosion and hardness of both 2024 and 6061 aircraft aluminum alloys. At room temperature, the work was completed $\left(25^{\circ} \mathrm{C}\right)$. With a salinity of 37.0 (milligrams per liter). The results of the chemical analysis of rainwater media are shown in Table 2. 
Table 2

Chemical analysis of Rain Water

\begin{tabular}{|ll|}
\hline Type of analysis & percentage \\
\hline $\mathrm{pH}$ & 5.7 \\
$\mathrm{EC}(\mu \mathrm{s} / \mathrm{Cm})$ & 65.03 \\
\hline $\mathrm{T} . \mathrm{D} . \mathrm{S} .(\mathrm{mg} / \mathrm{l})$ & 37.0 \\
\hline $\mathrm{Ca}^{+2}(\mathrm{mg} / \mathrm{l})$ & 4 \\
$\mathrm{Mg}^{+2}(\mathrm{mg} / \mathrm{l})$ & 4.8 \\
$\mathrm{CaCo}_{3}(\mathrm{mg} / \mathrm{l})$ & 30 \\
\hline $\mathrm{Cl}^{-}(\mathrm{mg} / \mathrm{l})$ & 1.15 \\
\hline $\mathrm{HCO}_{3}{ }^{-}(\mathrm{mg} / \mathrm{l})$ & 12.75 \\
\hline $\mathrm{SO}_{4}{ }^{-2}(\mathrm{mg} / \mathrm{l})$ & 2.83 \\
\hline $\mathrm{NO}_{3}{ }^{-}(\mathrm{mg} / \mathrm{l})$ & 0.88 \\
\hline $\mathrm{NO}_{2}{ }^{-}(\mathrm{mg} / \mathrm{l})$ & 0.003 \\
\hline
\end{tabular}

\subsection{Solution Heat treatment}

Both 2024 and 6061 aircraft aluminum alloys were treated with a solution treatment in this study to see how heat treatment affected corrosion resistance and hardness. The samples were solution treated in the lab furnace at $530{ }^{\circ} \mathrm{C}$ for 2 hours for $A A 6061$ and $490^{\circ} \mathrm{C}$ for 2 hours for AA 2024, then quenched in distilled water. Both alloys are aged for 1 and 2 hours at temperatures of $150,200,250$, and $300^{\circ} \mathrm{C}$.

\section{Results And Discussion:}

\subsection{Electrochemical Impedance Spectroscopy (EIS) before heat treatments in rainwater}

EIS test results of AA2024 and AA6061 alloy in rainwater are shown in Figure (1) and figure (2) and table (3) show the resistors and capacitors that had been gained from the Nyquist plots by using equivalent circuit with fit model Constant Phase Element (CPE) as shown in figure (3) for both AA2024 and AA6061.From figure (1) and figure (2) by comparing the resistance for AA2024 and AA6061 it is clear that, In AA6061 the resistance is higher than AA2024 in rainwater.

Table (3) the resistors and capacitors of AA2024 and AA6061 alloy before solution heat treatments in rainwater

\begin{tabular}{|llll|}
\hline Alloys & $\mathbf{R}_{\mathrm{p}}$ (ohms) & $\mathrm{R}_{\mathrm{u}}$ (ohms) & $\mathrm{C}_{\mathrm{f}}(\boldsymbol{\mu} \mathrm{F})$ \\
\hline 2024AA & $2.382 \times 10^{3}$ & 22.82 & 120.2 \\
\hline 6061AA & $2.317 \times 10^{3}$ & 38.23 & 109.0 \\
\hline
\end{tabular}

Where : 
$\mathrm{R}_{\mathrm{p}}=$ medium resistance

$\mathrm{R}_{\mathrm{u}}=$ metal resistance

$\mathrm{C}_{\mathrm{f}}=$ the metal -electrolyte interface

\subsection{Effect of solution treatment on electrochemical impedance spectroscopy of 2024 and 6061aircraft aluminum alloys}

The Nyquist curve for EIS test results of AA2024 and AA6061 alloy in rainwater after heat treatment are shown in Figs. 4, 5, 6, and 7. Table (4) and table (5) show the resistors and capacitors that had been gained from the Nyquist plots by using CPE fit for both AA2024 and AA6061.

In Fig. (4) shows EIS test results of AA2024 alloy after heat treatment in rainwater for AA2024 of temperature $\left(150,200,250\right.$, and $\left.300^{\circ} \mathrm{C}\right)$ for aging $1 \mathrm{hr}$, from these figure by comparing between the resistance and capacitors at the temperatures 150,200 and $250^{\circ} \mathrm{C}$ the resistance increase while at temperatures $300^{\circ} \mathrm{C}$ the resistance decrease.

Figure (5) shows EIS test results of AA2024 alloy after heat treatment in rainwater for AA2024 of temperature $\left(150,200,250\right.$, and $\left.300^{\circ} \mathrm{C}\right)$ for aging $2 \mathrm{hr}$, from these figure by comparing between the resistance and capacitors at the temperatures 150,200 , and $250^{\circ} \mathrm{C}$ the resistance increase while at temperature $300^{\circ} \mathrm{C}$ the resistance decrease.

Figure (6) shows EIS test results of AA6061 alloy after heat treatment in rainwater for AA6061 of temperature $\left(150,200,250\right.$, and $\left.300^{\circ} \mathrm{C}\right)$ for aging $1 \mathrm{hr}$, from these figure by comparing between the resistance and capacitors at the temperatures 150,200 and $250^{\circ} \mathrm{C}$ the resistance increase while at temperatures $300^{\circ} \mathrm{C}$ the resistance decrease.

In Fig. (7) shows EIS test results of AA6061 alloy after heat treatment in rainwater for AA6061 of temperature $\left(150,200,250\right.$, and $\left.300^{\circ} \mathrm{C}\right)$ for aging $2 \mathrm{hr}$, from these figure by comparing between the resistance and capacitors at the temperatures $200^{\circ} \mathrm{C}$ the resistance increase while at temperatures 150,250 and $300^{\circ} \mathrm{C}$ the resistance decrease.

Figure (8) and table (6) show phases obtain from XRD test. From these figure and table the maximum value for 2024AA of intensity was 100 at a position of $2 \theta=44.68$ for alloy 2024 aging treatment at temp. $250{ }^{\circ} \mathrm{C}$ for $2 \mathrm{hrs}$. For AA6061 the maximum value of intensity was 100 at a position $2 \theta=44.68$ for alloy 6061 aging treatment at temp. $300{ }^{\circ} \mathrm{C}$ for $1 \mathrm{hr}$. After heat treatments, $\mathrm{Al}_{2} \mathrm{Cu}$ and $\mathrm{Al}_{2} \mathrm{CuMg}$ phase formed in $2024 \mathrm{AA}$ while after heat treatments, $\mathrm{Mg}_{2} \mathrm{Si}$ phase formed in 6061 AA.

Figure (9) show SEM and EDS test results of AA2024 and AA6061 before and after solution heat treatment. From these tests, it is found that the change in the values of the resistors and capacitors in the EIS test are effected with the precipitated phases due to the solution treatment, as well as the formation of oxide and chloride layers as corrosion products due to rainwater environment.

Table (4) the resistors and capacitors of AA2024 alloy after solution heat treatments in rain water 


\begin{tabular}{|llll|}
\hline alloys & $\mathrm{R}_{\mathrm{p}}$ (ohms) & $\mathrm{R}_{\mathrm{u}}$ (ohms) & $\mathrm{C}_{\mathrm{f}}(\boldsymbol{\mu} \mathrm{F})$ \\
\hline 2024,150 oC, $1 \mathrm{~h}$ & $2.919 \times 10^{3}$ & 45.66 & 75.23 \\
\hline 2024,150 oC,2h & $1.993 \times 10^{3}$ & 37.72 & 135.0 \\
\hline 2024,200 oC,1h & $2.263 \times 10^{3}$ & 41.76 & 80.53 \\
\hline 2024,200 oC,2h & $3.408 \times 10^{3}$ & 34.22 & 40.38 \\
\hline 2024,250 oC,1h & $4.033 \times 10^{3}$ & 37.79 & 58.65 \\
\hline 2024,250 oC,2h & $2.802 \times 10^{3}$ & 51.92 & 176.8 \\
\hline 2024,300 oC,1h & $2.296 \times 10^{3}$ & 18.40 & 86.81 \\
\hline 2024,300 oC,2h & $1.556 \times 10^{3}$ & 26.93 & 288.0 \\
\hline
\end{tabular}

Table (5) the resistors and capacitors of AA6061 alloy after solution heat treatments in rainwater

\begin{tabular}{|llll|}
\hline alloys & $\mathrm{R}_{\mathrm{p}}$ (ohms) & $\mathrm{R}_{\mathrm{u}}$ (ohms) & $\mathrm{C}_{\mathrm{f}}(\mu \mathrm{F})$ \\
\hline $6061,150,{ }^{\circ} \mathrm{C} 1 \mathrm{~h}$ & $2.932 \times 10^{3}$ & 47.95 & 73.64 \\
\hline $6061,150^{\circ} \mathrm{C}, 2 \mathrm{~h}$ & 873.0 & 34.84 & 182.5 \\
\hline $6061,200^{\circ} \mathrm{C}, 1 \mathrm{~h}$ & 847.3 & 40.94 & 175.2 \\
\hline $6061,200^{\circ} \mathrm{C}, 2 \mathrm{~h}$ & $6.937 \times 10^{3}$ & 39.93 & 80.19 \\
\hline $6061,250^{\circ} \mathrm{C}, 1 \mathrm{~h}$ & $3.292 \times 10^{3}$ & 48.01 & 67.25 \\
\hline $6061,250^{\circ} \mathrm{C}, 2 \mathrm{~h}$ & $4.090 \times 10^{3}$ & 20.78 & 66.57 \\
\hline $6061,300^{\circ} \mathrm{C}, 1 \mathrm{~h}$ & $2.582 \times 10^{3}$ & 21.60 & 152.1 \\
\hline $6061,300^{\circ} \mathrm{C}, 2 \mathrm{~h}$ & $3.346 \times 10^{3}$ & 26.91 & 69.49 \\
\hline
\end{tabular}

Table (6) Phases obtain from XRD test 


\begin{tabular}{|c|c|c|c|c|}
\hline Alloys & phase & 2Theta & $\mathrm{l} / \mathrm{I}_{1}$ & $\begin{array}{l}\text { Crystal } \\
\text { system }\end{array}$ \\
\hline $\begin{array}{l}\text { AA2024 solution heat treatment and } \\
\text { aging at temp. } 250^{\circ} \mathrm{C} \text { for } 2 \mathrm{hrs} \text {. }\end{array}$ & Al & $\begin{array}{l}38.43,44.68,65.04 \\
78.19,78.44\end{array}$ & $81,100,97,29,97.65$ & Cubic \\
\hline $\begin{array}{l}\text { AA2024 solution heat treatment and } \\
\text { aging at temp. } 250^{\circ} \mathrm{C} \text { for } 2 \mathrm{hrs} \text {. }\end{array}$ & $\mathrm{Al}_{2} \mathrm{CuMg}$ & $\begin{array}{l}27.24,39.24 \\
42.88,44.68, \\
64.28,65.04,66.04 \\
78.19,78.44\end{array}$ & $\begin{array}{l}\text { 6.61, 9.49, } \\
4.10,100, \\
26.51,6.96, \\
97,29,6.96\end{array}$ & Orthorhombic \\
\hline $\begin{array}{l}\text { AA2024 solution heat treatment and } \\
\text { aging at temp. } 250^{\circ} \mathrm{C} \text { for } 2 \mathrm{hrs}\end{array}$ & $\mathrm{Al}_{2} \mathrm{Cu}$ & $\begin{array}{l}42.88,65.04,66.04 \\
78.44\end{array}$ & $4.10,97,6.96,6.96$ & Tetragonal \\
\hline $\begin{array}{l}\text { AA6061 solution heat treatment and } \\
\text { aging at temp. } 300^{\circ} \mathrm{C} \text { for } 1 \mathrm{hr} \text {. }\end{array}$ & Al & $\begin{array}{l}38.44,44.68,65.04 \\
78.16\end{array}$ & $44,100,53,30$ & Cubic \\
\hline $\begin{array}{l}\text { AA6061 solution heat treatment and } \\
\text { aging at temp. } 300^{\circ} \mathrm{C} \text { for } 1 \mathrm{hr} \text {. }\end{array}$ & $\mathrm{Mg}_{2} \mathrm{Si}$ & $40.12,78.16$ & $5.22,30$ & Cubic \\
\hline
\end{tabular}

\section{Conclusions}

1- In AA2024 alloys, the resistance values increase after heat treatment. Except for the case solution treatment and aged at $300{ }^{\circ} \mathrm{C}$ for 1 and $2 \mathrm{hr}$., the resistance values decrease. An increase in the resistance value means that the corrosion rate is decrease.

2- In AA6061 alloy, the resistance values after heat treatment increase for solution treatment and aged at temperatures 150,200 , and $250^{\circ} \mathrm{C}$ for $1 \mathrm{hr}$ and for the case of aging at $200^{\circ} \mathrm{C}$ for $2 \mathrm{hr}$.

3- The high resistance value was in alloy 2024 solution treatment and aged at temperature $250^{\circ} \mathrm{C}$ for $2 \mathrm{hr}$ and the lower value was in aged temperature $300^{\circ} \mathrm{C}$ for $1 \mathrm{hr}$. High capacitor value of alloy 2024 solution treatment and aged at temperature $300^{\circ} \mathrm{C}$ for $2 \mathrm{~h}$ and the lower value was in aged temperature $200^{\circ} \mathrm{C}$ for $2 \mathrm{~h}$.

4- The high resistance values of alloy 6061 solution treatment and aged at temperature $150^{\circ} \mathrm{C}$ for $1 \mathrm{hr}$ and the lower value was in aged temperature $250^{\circ} \mathrm{C}$ for $2 \mathrm{hr}$. High capacitor value of alloy 6061 solution treatment and aged at temperature $150{ }^{\circ} \mathrm{C}$ for $2 \mathrm{hr}$ and the lower value was in aged temperature $250{ }^{\circ} \mathrm{C}$ for $2 \mathrm{hr}$.

5-The compatibility type was Constant Phase Element (CPE) due to the formation of a layer of corrosive products which behaves like a coating layer.

\section{Declarations}

\section{Acknowledgments}

The authors would like to express their gratitude to the personnel of Mustansiriyah University in Baghdad, Iraq (www.upomustansiriyah.edu.iq) for their assistance with this project.

\section{References}

1. J. Gilbert Kaufman, "Introduction to Aluminum Alloys and Tempers"(ASM International, 2000) 
2. Heat Treating, Vol 4, ASM Handbook (ASM International, 1991)

3. J.R. Davis, Aluminum and Aluminum Alloys, in ASM Specially Handbook (ASM, International, Metal Park, Ohio, 1993)

4. W.D. Callister, Material Science and Engineering (John Wiley and Sons, New York, 1997)

5. ASM International Subject Guide (2015), Materials Park, Ohio

6. S.H. Avner, Introduction to Physical Metallurgy (McGraw-Hill International Book Company, Tokyo, 1982)

7. O.K. Abubakre, U.P. Mamaki, R.A. And Muriana (2009), "Investigation of the Quenching Properties of Selected Media on 6061 Aluminum Alloy", Journal of Minerals \& Materials Characterization \& Engineering, Vol. 8, No.4, pp 303315, USA

8. S.L. Pohlman, in ASM Handbook, Volume 13, Corrosion, edited by J. R. Davis. ASM International, Materials Parks, OH, 1987, pp. 80-103

9. "Corrosion of, Aluminum and Aluminum alloys"(ASM International, 1999)

10. E. Ghali, in Uhlig's Corrosion Handbook, 2nd edition, edited by R. W. Revie. Wiley, Hoboken, NJ, 2000, pp. 677-715

11. "Basics of Electrochemical Impedance Spectroscopy," Princeton Applied Research (2003) 1-13

12. A. Association. International alloy designations and chemical composition limits for wrought aluminum and wrought aluminum alloys. Teal Sheets 2009 cited Access (2009) accessed:22/7/2020;1-28Availablefrom: https://www.aluminum.org/sites/default/files/Teal\%20Sheet.pdf

\section{Figures}

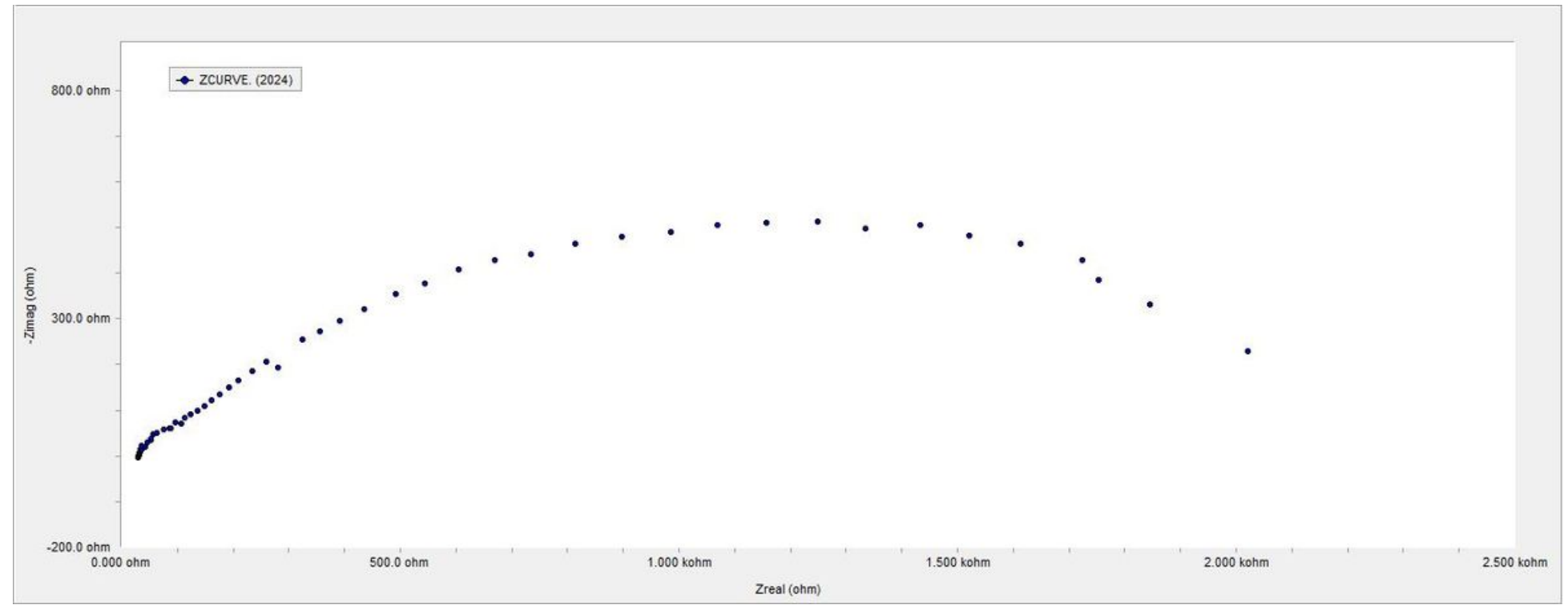

\section{Figure 1}

EIS test results of AA2024 alloys before solution heat treatment at rainwater 


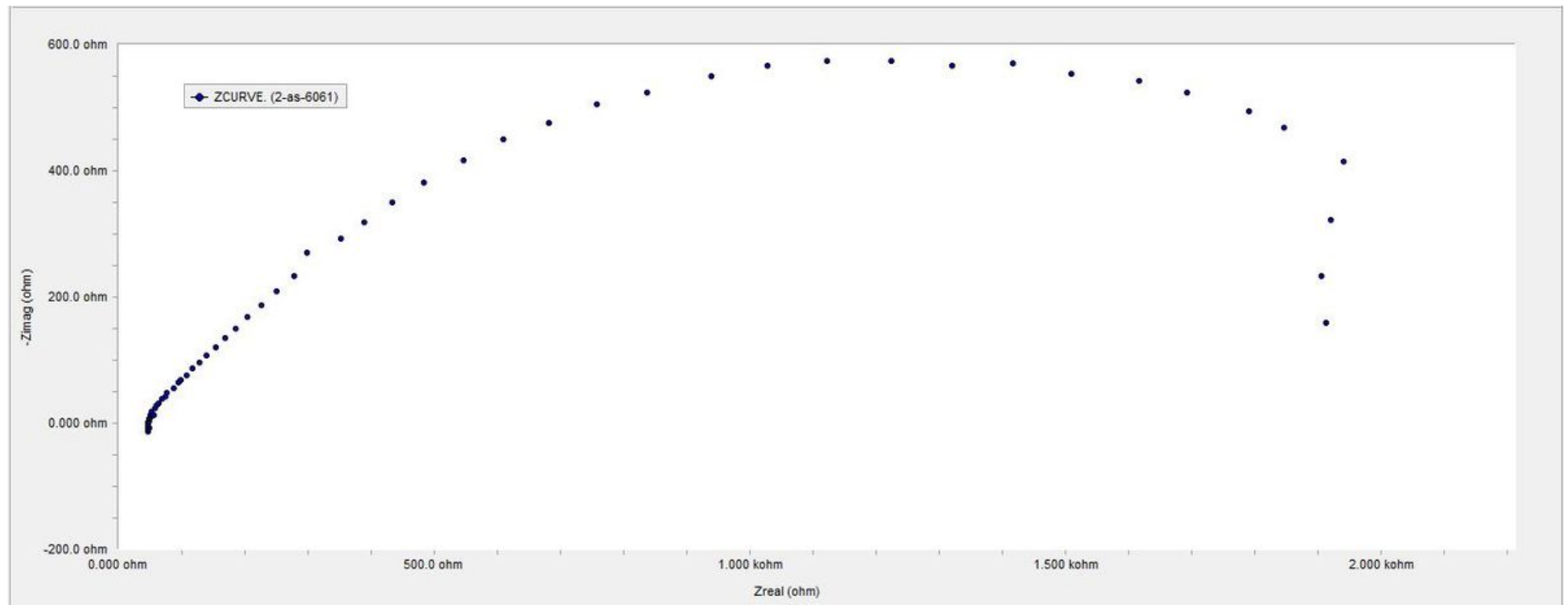

Figure 2

EIS test results of AA6061 alloys before solution heat treatment at rainwater

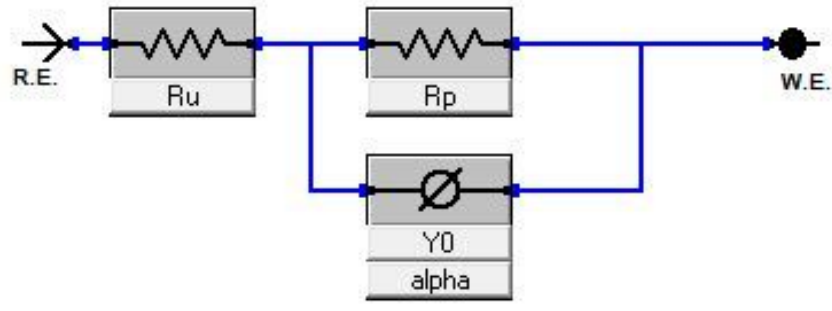

Figure 3

shown a model of Constant Phase Element $(C P E)(R p=$ medium resistance, $R u=$ metal resistance, $Y 0=C=$ the capacitance, a=generally 0.9-1.0 ( $a=1$ for an ideal Capacitor)

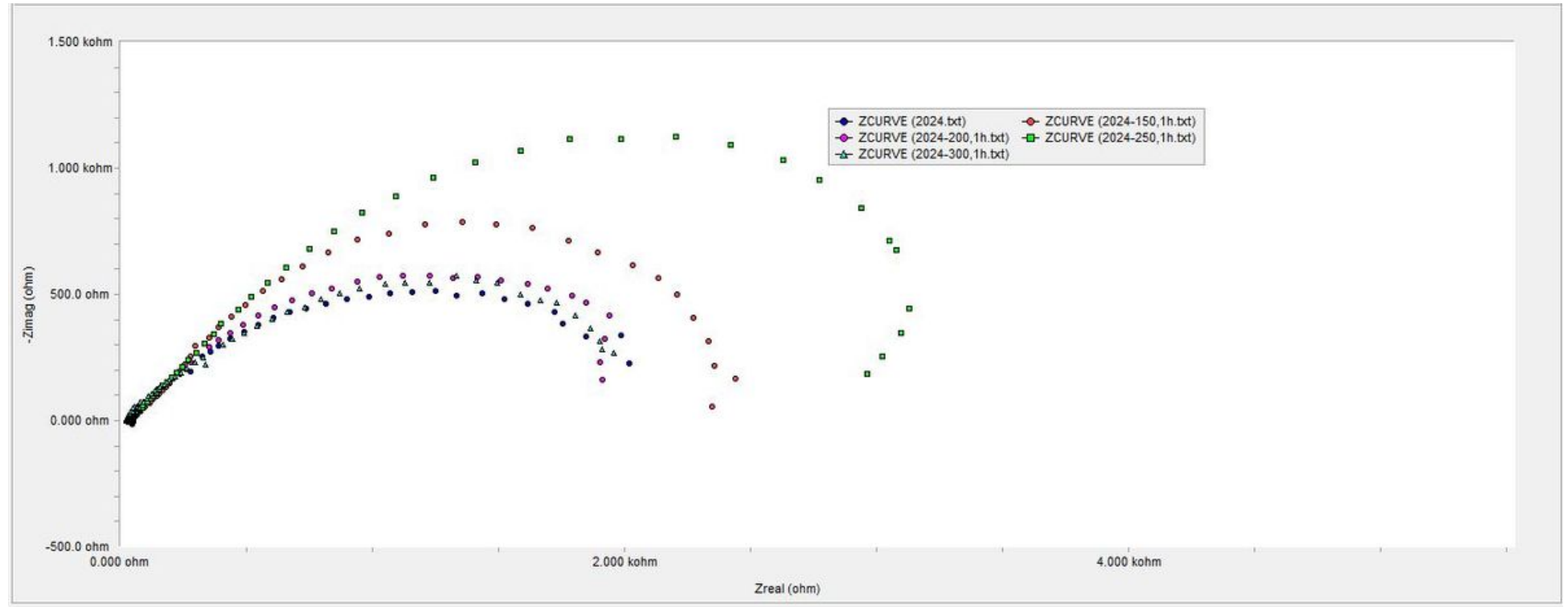

Figure 4 
shown Nyquist plot of AA2024 after solution heat treatment and aging at temperatures $(150,200,250$, and 300 oC) for $1 \mathrm{hr}$ in rainwater

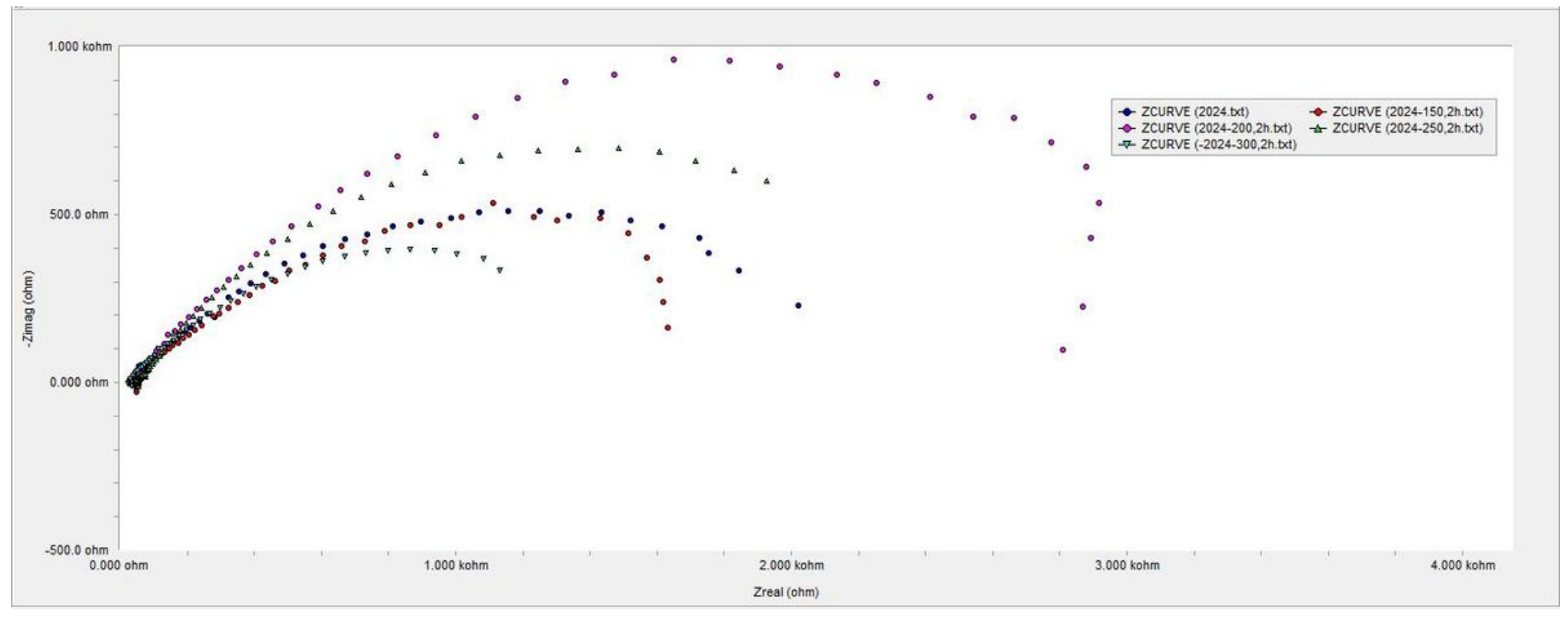

\section{Figure 5}

shown Nyquist plot of AA2024 after solution heat treatment and aging at temperatures $(150,200,250$, and 300 oC) for $2 \mathrm{hr}$ in rainwater

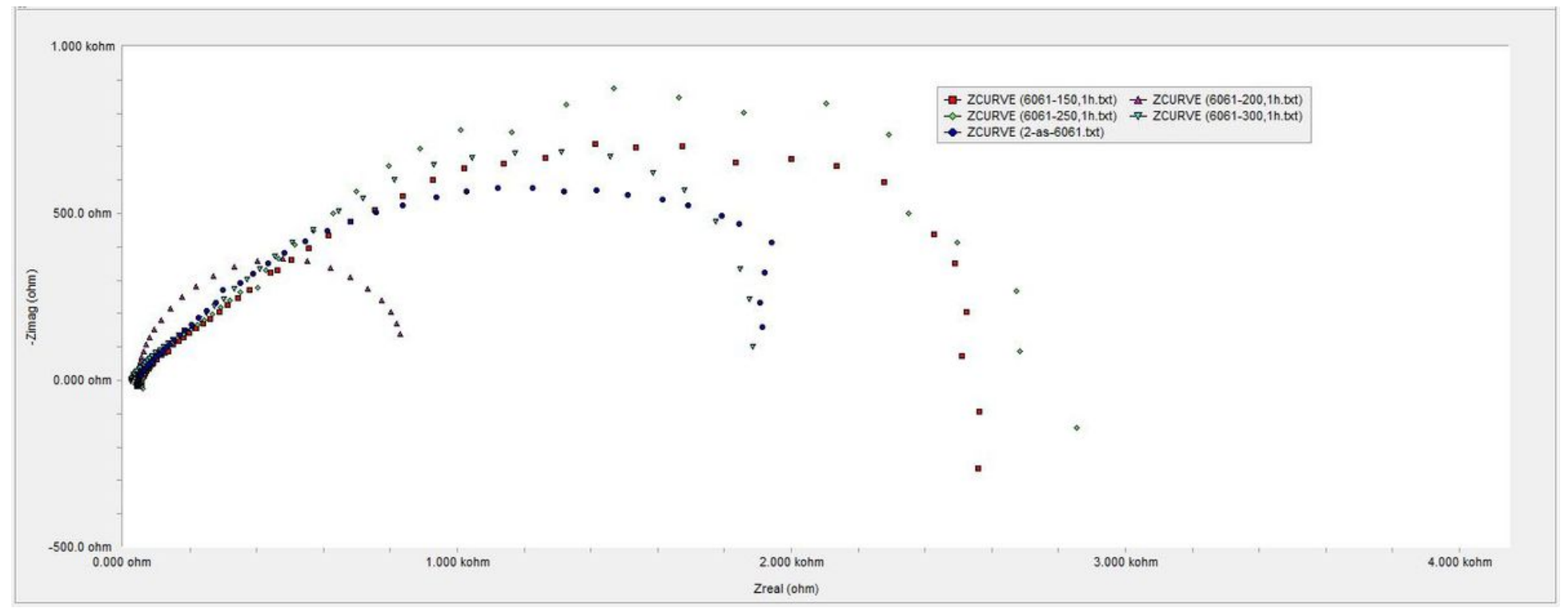

\section{Figure 6}

shown Nyquist plot of both AA6061 after solution heat treatment and aging at temperatures $(150,200,250$, and 300 oC) for $1 \mathrm{hr}$ in rainwater 


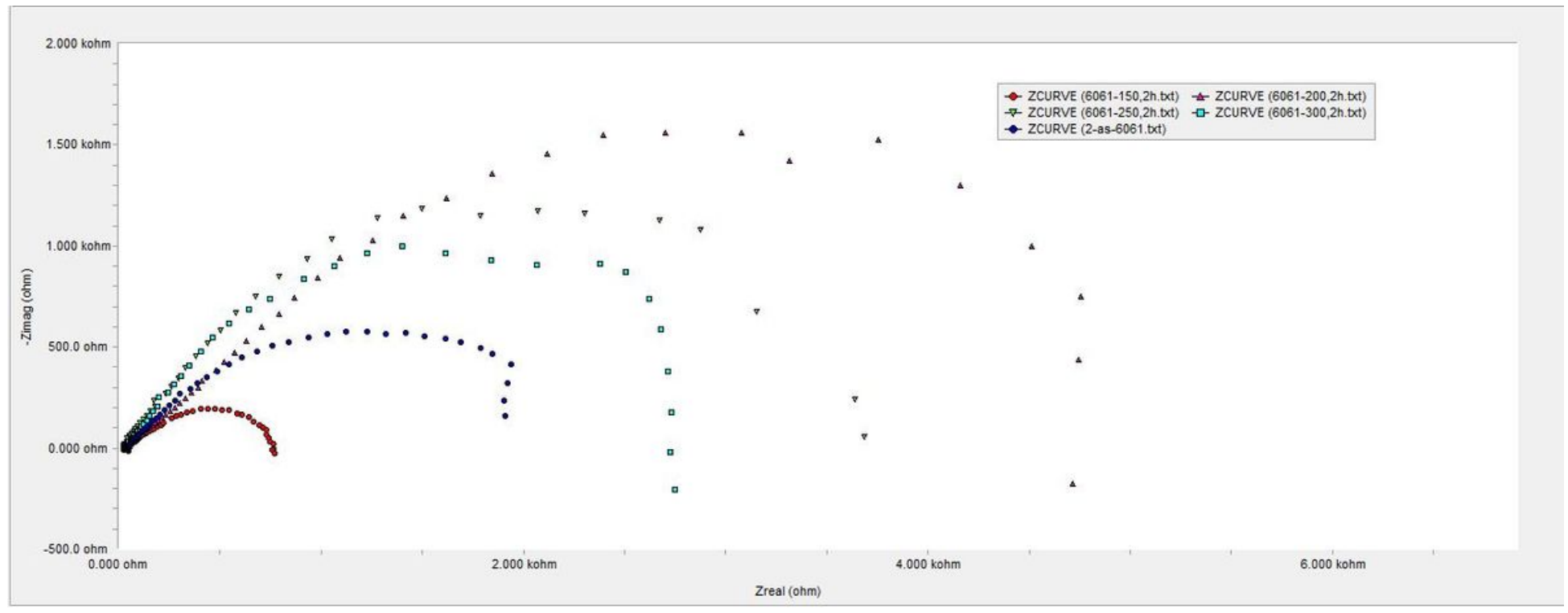

Figure 7

shown Nyquist plot of both AA6061 after solution heat treatment and aging at temperatures $(150,200,250$, and 300 oC) for $2 \mathrm{hr}$ in rainwater

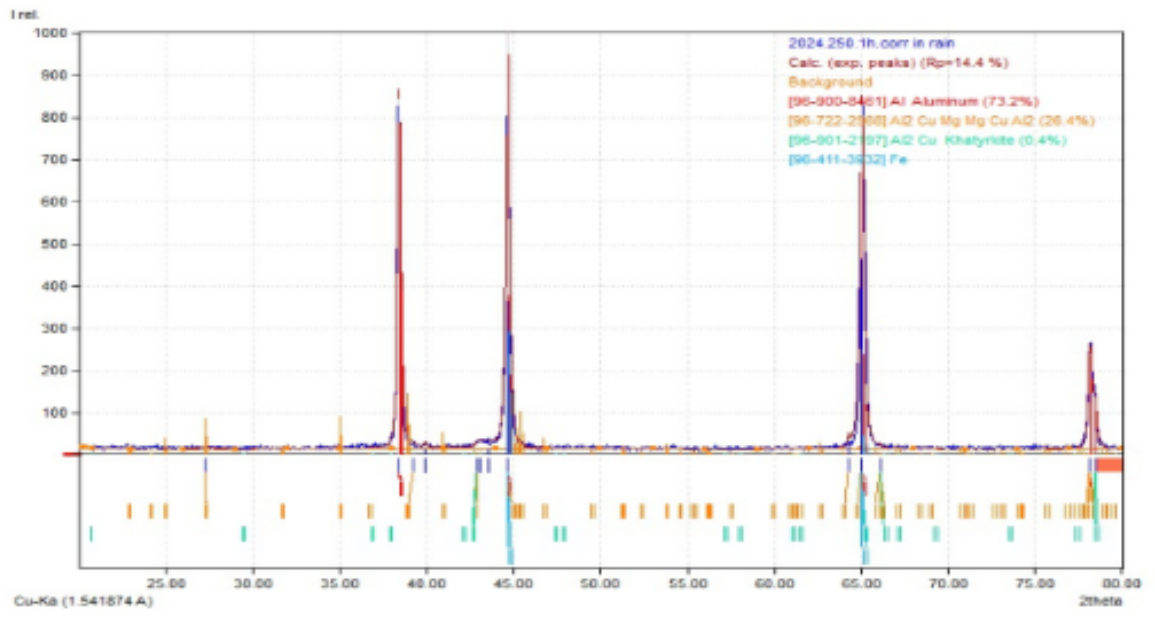

a)XRD test for alloy AA2024

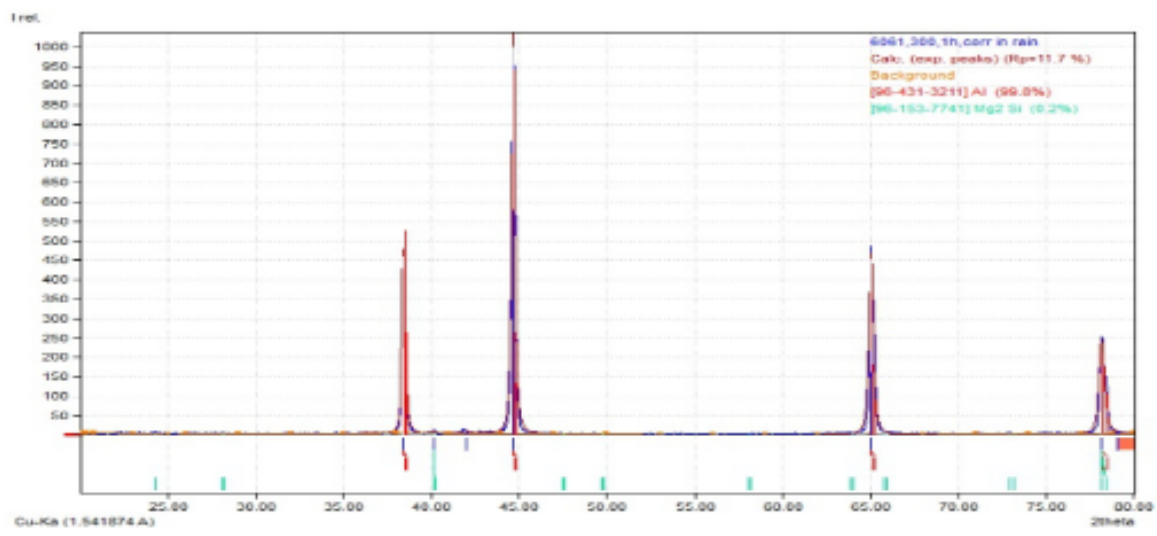

b) XRD test for alloy AA6061

Figure 8 
XRD inspection alloy a) alloy AA2024 solution heat treatment and aging at temp.250 oC for $1 \mathrm{hr}$. and b) alloy AA6061 solution heat treatment and aging at temp.300 oC for1hr.

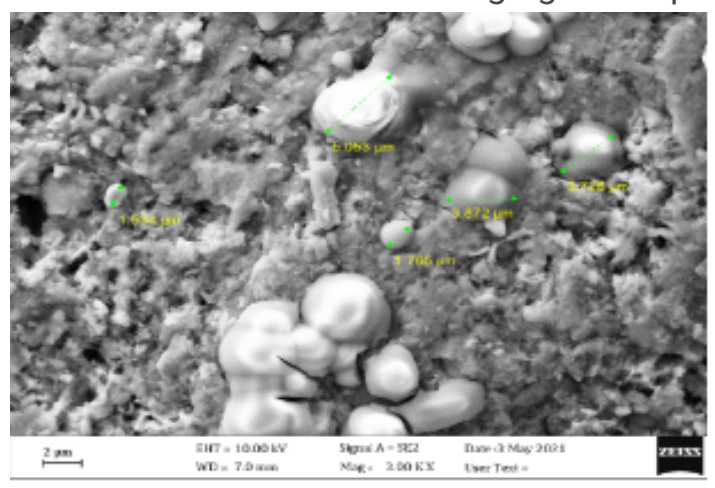

a) SEM test of AA2024, $3.00 \mathrm{kx}$

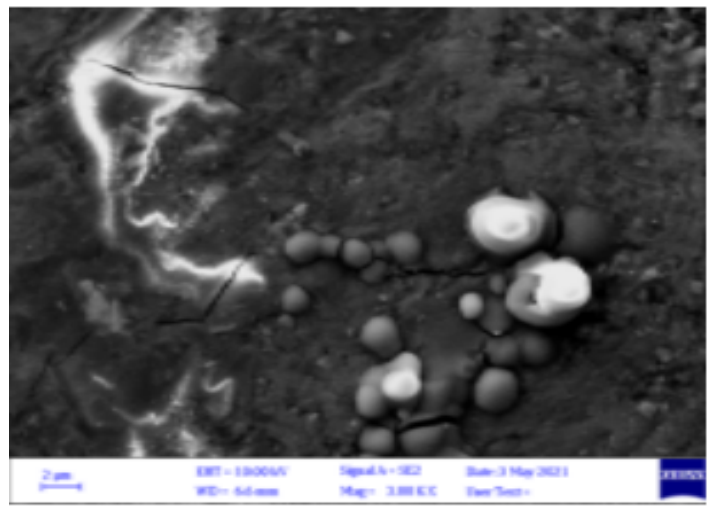

c) SEM test of AA6061, $3.00 \mathrm{kx}$

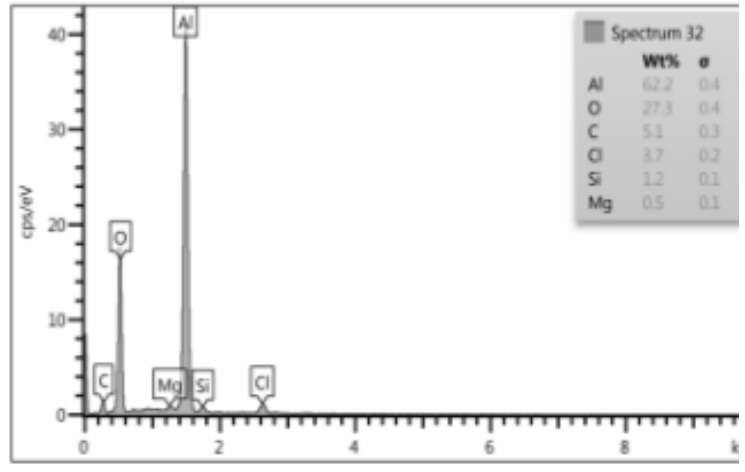

b) EDS test of AA2024

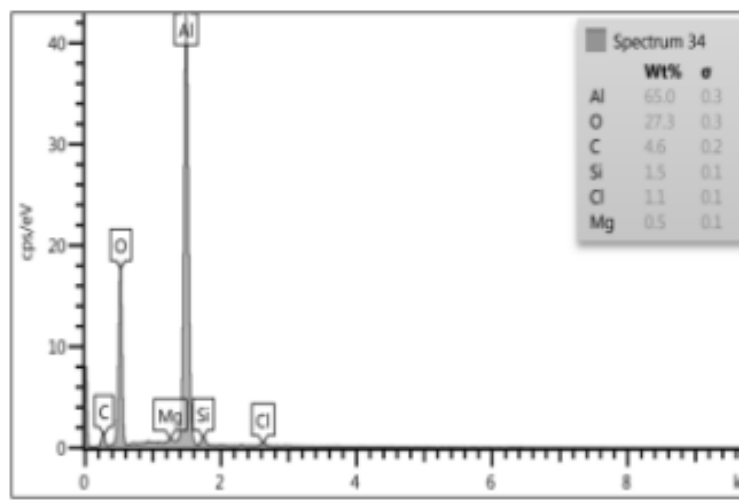

d) EDS test of AA6061

\section{Figure 9}

SEM and EDS test for a)and b) for alloy AA2024 solution heat treatment and aging at temp. 250 oC for $1 \mathrm{hr}$. c) and d) for alloy AA6061 solution heat treatment and aging at temp.300 oC for $1 \mathrm{hr}$. 